DOI: https://doi.org/10.24867/13NU01Joksimovic

\title{
SOCIJAL-DEMOGRAFSKE KARAKTERISTIKE PLAVLJENIH PODRUČJA BANJA LUKE SA TEORETSKIM OSVRTOM NA ASPEKT RODA
}

\section{SOCIAL-DEMOGRAPHIC CHARACTERISTICS OF THE FLOODING AREAS OF BANJA LUKA WITH THEORETICAL REVIEW OF THE GENDER ASPECT}

\section{Zorana Joksimović Šabaz, Fakultet tehničkih nauka, Novi Sad}

\section{Oblast - UPRAVLJANJE RIZIKOM OD KATASTROFALNIH DOGAĐAJA I POŽARA}

Kratak sadržaj - Istraživanjem je obuhvaćen uzorak od 38 domaćinstava u dva plavljena naselja grada Banja Luka - Česma i Lazarevo. Analizirani su socijal demografski podaci, visina evidentirane štete, karakteristike objekata $i$ informisanost stanovništva o merama zaštite $i$ prevenciji lokalne samouprave. Teoretsko uporište rada oslanja se na činjenicu da sistem nije rodno senzitivan $i$ da je najteži opravak marginalizovanih društvenih grupa.

Ključne reči: Poplave, Prevencija, Žene, Rod Intersekcionalnost

\begin{abstract}
The research included a sample of 38 households in two flooded settlements in the city of Banja Luka - Cesma and Lazarevo. Socio - demographic data, the amount of recorded damage, the characteristics of the facilities, the population awareness about the measures of protection and prevention of local government were analyzed. The theoretical basis of the work relies on the fact that the system is not gender sensitive and that the most difficult task is the recovery of marginalized social groups.
\end{abstract}

Keywords: Floods, Prevention, Women, Gender, Intersectionality

\section{UVOD}

Na našem području osete se svetske krize, a ugroženi smo i sopstvenim, najčeše izazvanih poplavama. Iako elementarne nepogode pogađaju sve kategorije stanovništva, ovaj rad ukazaće na opasnost rizika od poplava, potencijalne ili već nastale posledice i stanje sistema u kontekstu koji može imati različite društvene posledice na muškarce i žene, kao i na osetljive grupe stanovništva, zbog razlika $u$ stepenu ranjivosti i njihove socijalne isključenosti koje bitno utiču na njihovu sposobnost izbegavanja i saniranja rizika.

Postoji niz mera kojima se pribegava radi stvaranja otpornosti na hazarde, ali oni nisu jednako dostupne ni svim državama, niti svim pojedincima, iako se posledice često prožimaju celim svetom. Studija o rodnim aspektima prirodnih katastrofa iz 2007. godine, ukazuje na viši procenat stradanja žena u odnosu na muškarce [1].

\section{NAPOMENA:}

Ovaj rad proistekao je iz master rada čiji mentor je bila dr Mirjana Laban, vanr. prof.
Ta praksa je determinisana nametnutim rodnim ulogama, usvojenim društvenim normama i neravnopravnosti između polova. Žene i muškarci drugačije percipiraju opasnost, a različita sposobnost odgovara na nju uslovljava i nivo stradanja. Samim tim uspešnost oporavka jednog društva nakon razornog događaja može se posmatrati iiz perspektive roda.

Klimatske promene i sigurnost građana $u$ direktnoj su vezi. Suočavanje sa brojnim izazovima, zahtevalo je razvijanje novih pristupa $\mathrm{u}$ upravljanju rizicima $\mathrm{u}$ vanrednim situacijama. $\mathrm{Na}$ globalnom nivou oni su artikulisani primenom Kyoto ${ }^{1}$ okvira, koji ističe glavne pravce inovacija $\mathrm{i}$ promena $\mathrm{u}$ sistemu. Bosna i Hercegovina je ratifikovala Kyoto protokol u aprilu 2007. godine. Prioriteti definisani ovim planom se ne mogu postići bez uvođenja rodno osetljive politike. Manje od godinu dana nakon velikih poplava na teritoriji našeg regiona 2014. godine, u Japanu je održana svetska konferencija Ujedinjenih Nacija, gde je usvojen "naslednik" okvir za smanjenje rizika od katastrofa Sendai okvir. Bosna i Hercegovina je jedna od 187 zemalja potpisnica.

Dokument, takođe, ističe značaj rodno osetljive politike delovanja: "Vlade treba da uključe relevantne aktere i zainteresovane strane, uključujući žene, decu, mlade, osobe sa invaliditetom, siromašne, migrante, pripadnike/ce tradicionalnih zajednica, volontere, profesionalce i starije osobe u kreiranju i primeni politike, planova i standarda" [2]. Ovaj rad baviće se demografskim karakteristikama plavljenih područja sa teoretskim osvrtom na aspekt roda, a na primeru - Banja Luka - poplave 2014. godine.

\section{REZULTATI ISTRAŽIVANJA}

Rezultati istraživanja obrađeni su analitičko-statističkim alatom SPSS uz primenu deskriptive statistike. Uzorak čini 38 stambenih objekata u dva Banjalučka naselja Česma i Lazarevo, 29, tj. 76.3\% objekata je iz naselja Česma, dok je 9, tj. 23.7\% iz naselja Lazarevo (tabela 1). U poplavama u maju 2014. godine u uzorku dva naselja stradala je jedna osoba.

${ }^{1} \mathrm{U}$ januaru 2005.godine, 168 vlada usvojilo je desetogodišnji plan za zaštitu sveta od prirodnih opasnosti na Svetskoj konferenciji o smanjenju katastrofa, održanoj u Kobeu, Kyoto, Japan. https://unfccc.int/kyoto_protocol (20.10.2020.) 


\begin{tabular}{|l|l|r|r|r|r|}
\hline & & & & Valid & Cumulative \\
Prequency & Percent & Percent & Percent \\
\hline \multirow{2}{*}{ Valid } & Lazarevo & 9 & 23,7 & 23,7 & 23,7 \\
\cline { 2 - 6 } & Cesma & 29 & 76,3 & 76,3 & 100,0 \\
\cline { 2 - 6 } & Total & 38 & 100,0 & 100,0 & \\
\hline
\end{tabular}

Tabela 1. Broj domaćinstava po naseljima

Ukupno 133 stanovnika (60 muškaraca, 61 žena, 11 dece). Broj zaposlenih u domaćinstvu je 61, što je manje od polovine uzorka (45.9\%) prema tabeli 2 .

\begin{tabular}{|l|l|l|}
\hline & N & Sum \\
\hline ukupan broj član. domaćinstva & 38 & 133 \\
\hline broj muških članova porodice & 38 & 60 \\
\hline broj ženskih članova porodice & 38 & 61 \\
\hline broj dece u domaćinstvu & 38 & 11 \\
\hline broj zaposlenih član. u domać. & 38 & 61 \\
\hline Valid N (listwise) & 38 & \\
\hline
\end{tabular}

Tabela 2. Broj članova domaćinstava

Prosečna starost članova domaćinstva je nešto iznad 47 godina života, a najstarija stanovnica naselja Česma ima 80 godina. Ona živi sama sa izuzetno niskim primanjima i tokom poplava u maju 2014. godine svo svoje pokućanstvo je izgubila, jer nije mogla sama da ga prenese na višu etažu stambenog objekta, lokalna zajednica joj nije obezbedila pomoć, a komšije su spašavale svoje porodice $\mathrm{i}$ imovinu. Bila je jedna od najsaradljivijih ispitanika/ca.

Maloletnih i iznad starosne granice za penziju je $28.9 \%$ populacije uzorka.

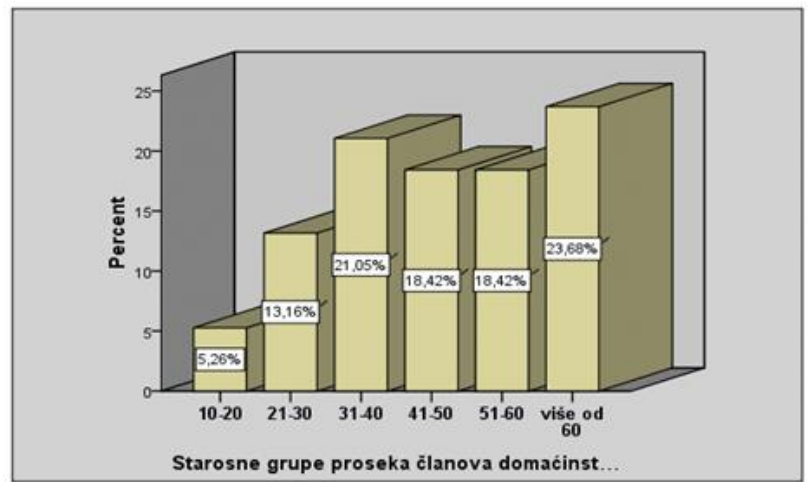

Grafikon 1. Starosne grupe proseka ispitanika $u$ godinama

\section{STAMBENI USLOVI}

Svi objekti u oba naselju po tipu pripadaju stambenom objektu - porodična kuća.

Većina parcela $(65.8 \%)$ ne prelazi veličinu od $500 \mathrm{~m}^{2}$, dok je od toga trećina manja čak i od $300 \mathrm{~m}^{2}$. Veličina parcele, kao i veličina i starost objekta na parceli, upućuje na socijalno - ekonomski staus ispitanika o čemu će više biti reči tokom analize novčanih primanja, štete od poplava i nedovoljnoj pomoći države (grafikon 2). Najveći broj porodičnih kuća stariji je od pola veka (36.84\%), dok je $26.32 \%$ objekata starosti između $30-50$ godina. Najmanji je procenat novo- zidanih porodičnih kuća, a pažnju privlači njihova izgradnja bliže vodi nego što je zakonom predviđeno i posedovanje građevinskih dozvola za upravo takve objekte (grafikon 3).
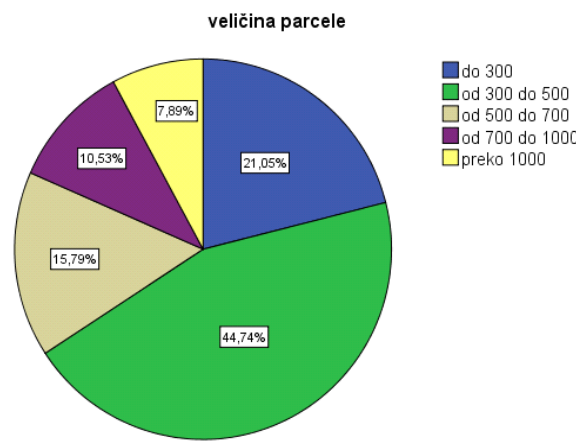

Grafikon 2. Veličina parcele

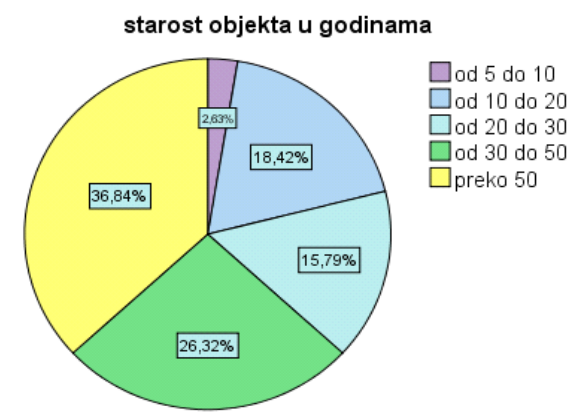

Grafikon 3. Starost porodične kuće

Objekti koji su u postupku dobijanja građevinske dozvole su ili tek izgrađeni (nakon poplava 2014.) ili su iz grupe starijih objekata, a zahtev za legalizaciju je podnet u skorijem periodu (grafikon 4). Samim tim se zaključuje da se decenijama nije vodilo računa o izgradnji i dokumentaciji, a da su se nakon prirodne nepogode koja je zadesila ova naselja, stanovništvo i opština pozvali na odgovornije delovanje.

Planskom izgradnjom se stvaraju povoljni uslovi za život, rad i zdravlje čoveka i dugoročno upravljanje prirodnim dobrima. Moraju postojati mere u oblasti prostornog planiranja. Izradom različitih vrsta dokumenata iz oblasti prostornog uređenja (strateških i detaljnih prostornih planova) i njihovom implementacijom, može se u velikoj meri uticati na smanjenje negativnih efekata poplava $\mathrm{i}$ klizišta na stambeni sektor. Postojeći zakonski okvir iz oblasti prostornog planiranja pruža dobar osnov za smanjenje rizika od poplava i klizišta $u$ odnosu na stambeni fond. Doslednom primenom zakonske regulative i izradom zakonom obaveznih dokumenata prostornog uređenja, koji između ostalog definišu namenu prostora, te njihovom implementacijom, poplave i klizišta bi zasigurno predstavljale manji rizik za stambeni sektor.

U maju 2014. godine, od ukupnog uzorka je plavljeno 35 objekata, od kojih je 8 plavljeno više puta u posljednjih 10 godina, dok samo 3 stambena objekta nisu plavljena. U tabeli 5 prikazana je povezanost udaljenosti od korita reke i njegovog stradanja usled poplava u poslednjoj deceniji. Objekti stariji od 20 godina zidani su na većoj udaljenosti od vode, dok su moderniji objekti postavljeni uz samu reku, a plavljeni samo jednom ili dva puta jer su stari manje od decenije. 


\begin{tabular}{|c|c|c|c|c|c|}
\hline & & & \multicolumn{2}{|c|}{$\begin{array}{c}\text { Da li je } \\
\text { objekat } \\
\text { plavljen u } \\
\text { poseldnjih } \\
10 \text { godina? }\end{array}$} & \multirow[b]{2}{*}{ Total } \\
\hline & & & $\mathrm{da}$ & ne & \\
\hline \multirow{15}{*}{$\begin{array}{l}\text { udaljenost } \\
\text { objekta od } \\
\text { korita reke }\end{array}$} & \multirow[t]{3}{*}{ do $50 \mathrm{~m}$} & Count & 16 & 1 & 17 \\
\hline & & & & & \\
\hline & & $\begin{array}{l}\text { Da li je objekat } \\
\text { plavljen u } \\
\text { poseldnjih } 10 \\
\text { godina? }\end{array}$ & $\begin{array}{r}45,7 \\
\%\end{array}$ & $33,3 \%$ & $44,7 \%$ \\
\hline & \multirow{3}{*}{$\begin{array}{l}\text { od } 50 \text { do } \\
100 \mathrm{~m}\end{array}$} & Count & 9 & 0 & 9 \\
\hline & & & & & \\
\hline & & $\begin{array}{l}\text { Da li je objekat } \\
\text { plavljen u } \\
\text { poseldnjih } 10 \\
\text { godina? }\end{array}$ & $25,7 \%$ & $0 \%$ & $23,7 \%$ \\
\hline & \multirow{3}{*}{$\begin{array}{lr}\text { od } \quad 100 \\
\text { do } 300 \mathrm{~m}\end{array}$} & Count & 10 & 0 & 10 \\
\hline & & & & & \\
\hline & & $\begin{array}{l}\text { Da li je objekat } \\
\text { plavljen u } \\
\text { poseldnjih } 10 \\
\text { godina? }\end{array}$ & $28,6 \%$ &, $0 \%$ & $26,3 \%$ \\
\hline & \multirow{3}{*}{$\begin{array}{lr}\text { od } & 300 \\
\text { do } 500 \mathrm{~m}\end{array}$} & Count & 0 & 1 & 1 \\
\hline & & & & & \\
\hline & & $\begin{array}{l}\text { Da li je objekat } \\
\text { plavljen u } \\
\text { poseldnjih } 10 \\
\text { godina? }\end{array}$ & $0 \%$ & $33,3 \%$ & $2,6 \%$ \\
\hline & \multirow{3}{*}{$\begin{array}{l}\text { preko } \\
500 \mathrm{~m}\end{array}$} & Count & 0 & 1 & 1 \\
\hline & & & & & \\
\hline & & $\begin{array}{l}\text { Da li je objekat } \\
\text { plavljen u } \\
\text { poseldnjih } 10 \\
\text { godina? }\end{array}$ & $0 \%$ & $33,3 \%$ & $2,6 \%$ \\
\hline
\end{tabular}

Tabela 4. Povezanost udaljenosti objekta od korita $i$ njegovog plavljenja u poslednjoj deceniji

\section{MATERIJALNA ŠTETA}

$\mathrm{Na}$ svim plavljenim objektima je evidentirana šteta. Visina štete je izražena $\mathrm{u} K \mathrm{KM}$, polovina plavljenih objekata pretrpela je materijalne gubitke $\mathrm{u}$ visini od $15.000-20.000 \mathrm{KM}$, a četvrtina od $10.000-15.000 \mathrm{KM}$ (grafikon 4), što je znatno više od vrednosti koju je refundirala država - $5.000 \mathrm{KM}$. Ukupna prosečna šteta izračunata je u visini od $19.770 \mathrm{KM}$.

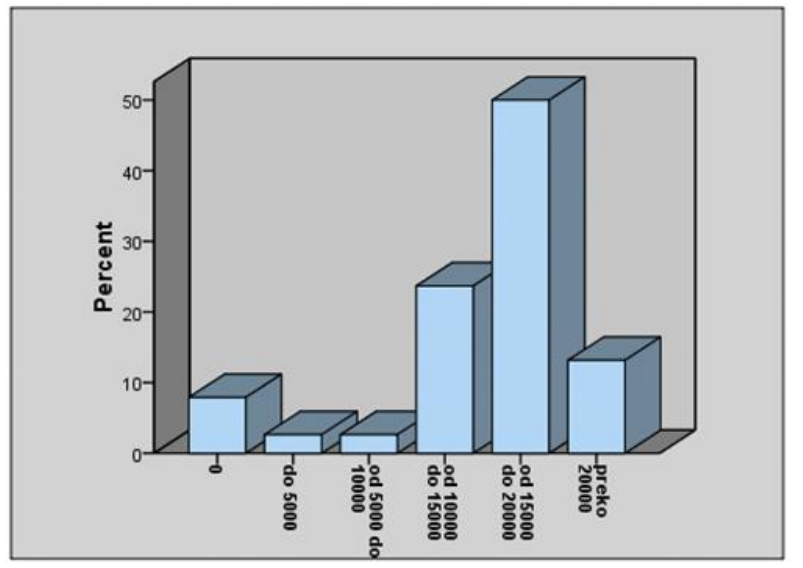

Grafikon 4. Visina štete na plavljenim objektima u KM

Iako je država pomogla finansijski stanovništvu čiji su objekti stradali u poplavama 2014. godine, visina nadoknade kod $60 \%$ oštećenih nije dosegla ni $20 \%$ visine realne štete. Od $20-40 \%$ štete je nadoknađeno državnom pomoći kod $22.86 \%$ domaćinstava, a samo $17.14 \%$ uspelo je da do polovine gubitka nadoknadi uz pomoć države.

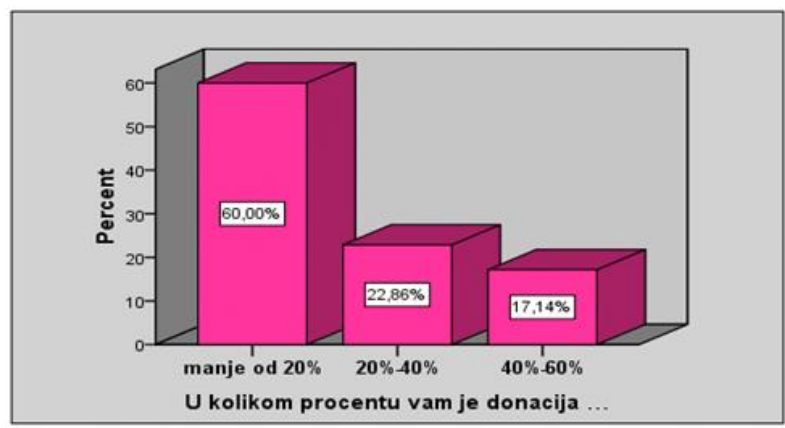

Grafikon 5. Visina pomoći države u nadoknadi štete

U 80\% domaćinstava nije postojala materijalna šteta usled gubitka životinja, dok je najveća šteta u visini od 700 $1000 \mathrm{KM}$ evidentirana u jednom domaćinstvu. Većina ispitanika/ca, koji su imali kućne ljubimce u vreme poplave, izjasnili/le su se o strahu i brizi koju su imali/le za njihovu bezbednost (grafikon 5).

\section{MESEČNA PRIMANJA}

U više od polovine domaćinstava zaposlena je jedna do dve osobe, tako da u 36.84\% domaćinstava finansijski doprinose dve osobe, a u $23.68 \%$ po jedna, dok 21 . $05 \%$ domaćinstava nema ni jednu zaposlenu osobu.

\begin{tabular}{|c|c|c|c|c|c|c|c|}
\hline & \multicolumn{5}{|c|}{$\begin{array}{c}\text { mesečna primanja članova u } \\
\mathrm{KM}\end{array}$} & \multirow[b]{2}{*}{ Total } \\
\hline & & $\begin{array}{c}\text { do } \\
500\end{array}$ & $\begin{array}{c}\text { od } \\
500 \\
\text { do } \\
1000\end{array}$ & $\begin{array}{c}\text { od } \\
1000 \\
\text { do } \\
1500\end{array}$ & $\begin{array}{c}\text { od } \\
1500 \\
\text { do } \\
2000\end{array}$ & $\begin{array}{l}\text { preko } \\
2000\end{array}$ & \\
\hline \multirow{5}{*}{$\begin{array}{l}\text { broj } \\
\text { zaposlenih } \\
\text { članova u } \\
\text { domaćinstvu }\end{array}$} & 0 & 6 & 2 & 0 & 0 & 0 & 8 \\
\hline & 1 & 4 & 5 & 0 & 0 & 0 & 9 \\
\hline & 2 & 0 & 4 & 6 & 3 & 1 & 14 \\
\hline & 3 & 0 & 2 & 1 & 2 & 1 & 6 \\
\hline & 6 & 0 & 0 & 1 & 0 & 0 & 1 \\
\hline \multicolumn{2}{|l|}{ Total } & 10 & 13 & 8 & 5 & 2 & 38 \\
\hline
\end{tabular}

Tabela 5. Broj zaposlenih članova domaćinstva $i$ ukupn kućni budžet

U tabeli 5 prikazan je broj zaposlenih članova domaćinstava i ukupna mesečna primanja svakog domaćinstva. Samo dva domaćinstva prelaze visinu prosečne potrošačke korpe u Republici Srpskoj. Rezultati istraživanja upućuju na siromaštvo u plavljenim područjima. S obzirom na visinu štete na porodičnim kućama, nedovoljnu finansijsku pomoć od države i niska mesečna primanja, sve ukazuje na trežak oporavak pogođene populacije usled egzistiranja na granici siromaštva.

"Kada je u pitanju javni sektor, onda treba istaći podatke prema kojima je ukupno 210.000 građana pogođeno delimičnom ili potpunom obustavom javnih usluga, od čega je 50.000 iz najugroženijih grupa kojima nije mogla biti isplaćena naknada od strane Centra za socijalni rad" [3]. 


\section{MERE ZAŠTITE}

Kada je reč o merama zaštite, ispitanici/ce su u vrlo malom procentu informisani o merama zaštite, svega $18.42 \%$, dok je $44.74 \%$ delimično informisano, a $36.84 \%$ nije uopšte (grafikon 6). Ovaj podatak je zabrinavajući, jer su na tom lokalitetu stanovnici već pretrpeli velike štete i više poplava, a još uvek znaju vrlo malo o načinu na koji bi mogli da se zaštite. Prema rezultatima istraživanja ispitanici/ce bi se u $94.7 \%$ slučajeva evakuisali iz plavljenog područja, a $73.7 \%$ bi premestili stvari na sigurnije mesto.

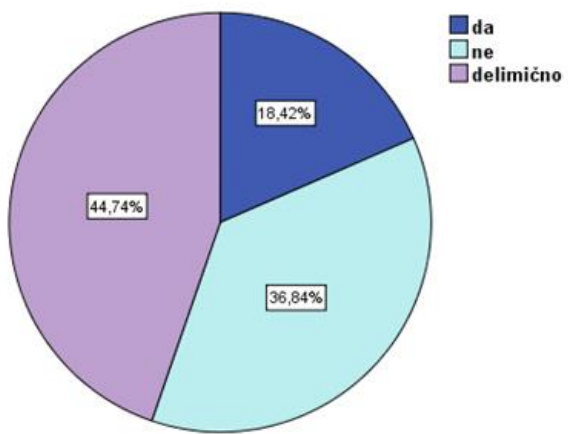

Grafikon 6. Informisanost ispitanika o zaštitnim merama

Na pitanje da li su gradske vlasti preduzele sve potrebne mere zaštite za naredni period, $60.53 \%$ ispitanika je odgovorilo negativno. Mali procenat je neobavešten, svega $2.63 \%$ dok ostali smatraju da se mere zaštite od strane gradske vlasti preduzete delimično ili malo.

Tokom terenskog istraživanja za potrebe ovog rada (2019), uočeno je da oštećeni nasip na ulazu u naselje Česma još uvek nije saniran.

\section{ZAKLJUČAK}

Rezultati istraživanja pokazuju da od 38 parcela u uzorku koje se nalaze u blizini reka Vrbas i Vrbanja i smatraju se ugroženim od poplava, ima najviše malih parcela, veličine od 300 do $500 \mathrm{~m}^{2}-(44,7 \%)$, a najviše objekata - $(36,8 \%)$ udaljeno je od korita reka do $100 \mathrm{~m}$. Samo polovina objekata poseduje građevinsku dozvolu, a od toga 6 je izgrađeno na udaljenosti od vode manjoj od 50 metara. Na toj udaljenosti nalazi se ukupno trećina objekata, što ih čini rizičnom gradnjom.

U maju 2014. godine, plavljeno je $71 \%$ objekata. Prosek štete u domaćinstvima iznosio je nešto manje od 20.000 KM, a država je refundirala samo 5.000 KM. Analizom mesečnih prihoda, ispitivana populacija spada $u$ siromašnu, a 3/4 štete oštećeni su snosili sami. Iako žive u ugroženim područjima, više puta plavljenim, čak 31,6\% stanovnika je potpuno neinformisano o zaštitnim merama od poplava, dok je polovina informisana delimično.

Politička i birokratska elita mora biti svesna neophodnosti delovanja u cilju smanjenja rizika od katastrofalnih događaja. Treba poštovati usvojenu legislativu o planovima prevencije, razvijati strategiju i pokrenuti edukaciju kako nadležnih kadrova, tako i stanovništva. Evidentiranje, kategorisanje i prioritetno delovanje prema marginalizovanim društvenim grupama - žene, deca, siromašni, osobe sa invaliditetom, stari, samohrani roditelji, itd.

Nepostojanje baza podataka i dokumenata u Republici Srpskoj (BiH) o postupanju u svrhu prevencije je problematično i uzrok je nevidljivosti rodnih elemenata. Nepostojanje rodno senzitivnog strateškog pristupa rezultira time da se ne uvide različite potrebe žena $i$ muškaraca i ostalih drštvenih grupa, a u cilju spašavanja i oporavka. Iako su se žene prve neformalno organizovale da pruže svu podršku bržem izlasku iz krize, nisu bile uključene $\mathrm{u}$ proces planiranja programa i javnih politika delovanja ni nakon razornog događaja.

Prikupljanjem i analizom podataka o hazardima podiže se nivo prevencije i pripremljenosti. Strategijsko planiranje reagovanja na hazarde zahteva međunarodnu saradnju, a povezanost između smanjenja uticaja katastrofa i siromaštva zahteva učestvovanje svih interesnih grupa na lokalnom, državnom, regionalnom i međuregionalnom nivou.

Sa stanovišta socijalnog aspekata evidentno je da marginalizovane društvene grupe imaju lošije fizičke i finansijske uslove da predvide, prežive i oporave se od razornih događaja te je intersekcionalni pristup ključan $\mathrm{u}$ kategorisanju ranjivosti ljudske zajednice i kreiranja plana oporavka. Naprednji rezultati ublažavanja efekata razornih događaja bili bi dosežniji uz uspešnu politiku smanjenja siromaštva. Takva sprega postoji i između rodne (ne)ravnopravnosti i preživljavanja uz oporavak, jer su marginalizovane grupe društva nevidljive u sistemu spašavanja, posebno žene u državama izražene patrijahalne kulture. Poboljšanjem statusa žena u jednom društvu, smanjuje se njegova ranjivost od prirodnih katastrofa. Koliko prirodna razaranja modernog sveta mogu biti antropogena, toliko mogu biti i posledice, jer su determinisane uslovima zajednice koju su zadesile.

\section{LITERATURA}

[1] Neumayer, E., \& Plumper, T. (2007). The gendered nature of natural disasters: The impact of catastrophic events on the gender gap in life expectancy, 19812002. Annals of the Association of American Geographers, 97(3), 551-566.

[2] Sendai framework for disaster risk reduction 20152030: chrome-

extension://gphandlahdpffmccakmbngmbjnjiiahp/https:// www.preventionweb.net/files/43291_sendaiframeworkfor drren.pdf

[3] Živanović, C., Komarčević, M., i Marković, M. (2014). Dimenzije infrastrukturne ranjivosti ilustrirane na primjeru katastrofalnih poplava u svibnju 2014. u BiH. Dani kriznog upravljanja, 235.

\section{Kratka biografija:}

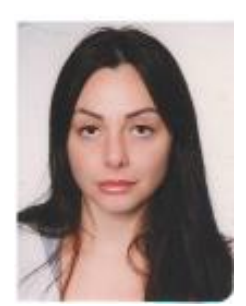

Zorana Joksimović Šabaz rođena je u Vršcu 1983. godine. Na Fakultetu tehničkih nauka zvanje Master inženjerskog menadžmenta stekla je 2008. godine na studijskom programu Upravljanje ljudskim resursima. Kandidatkinja je za odbranu doktorske teze na Univerzitetu u Novom Sadu, /ACIMSI - Rodne studije. 